\title{
INNOVATIONS IN EDUCATION
}

\section{Addressing Physicians' Impaired Communication Skills}

\author{
Barry Egener, MD \\ The Foundation for Medical Excellence, Portland, OR, USA.
}

INTRODUCTION: Deficient physician communication skills can lead to complaints by patients and colleagues. While there are many communication training courses for physicians, there are few descriptions of programs that address their deficiencies.

AIM: This report describes the use of a coaching model developed by the author to remediate inadequate communication skills.

PROGRAM DESCRIPTION: The coaching model consists of a discrete set of communication skills that are gradually integrated into professional activities while debriefing that process in a supportive relationship.

PROGRAM EVALUATION: Outcomes are provided for the first 13 physicians coached after the approach was standardized. On a Likert scale (range, 1-7), with 7 expressing "high satisfaction," all participants rated the consultation in the 5-7 range (mean, 6.3), and all supervisors rated the consultation in the 6-7 range (mean, 6.7).

DISCUSSION: A coaching model is effective in improving communication skills deemed inadequate by physicians' patients and colleagues. Future work should evaluate the impact of integrating coaching into health care organizations and on developing new tools to augment coaching.

KEY WORDS: physician communication; communication training; coaching model.

J Gen Intern Med 23(11):1890-5

DOI: $10.1007 /$ s1 1606-008-0778-7

(C) Society of General Internal Medicine 2008

\begin{abstract}
A variety of pressures have made health care organizations less tolerant of behaviors that alienate patients or other staff. Physicians whose patients leave a practice or who are inefficient jeopardize the financial viability of a practice. Physicians who conflict with other members of the health care team may jeopardize patient safety or make their institutions vulnerable to allegations of tolerating a hostile work environment. When behaviors deviate substantially from professional norms, they may capture the attention of clinic administrators, state medical boards or the medical executive committees of the hospitals where physicians practice. In the past, unless
\end{abstract}

Received October 4, 2007

Revised June 11, 2008

Accepted August 14, 2008

Published online September 5, 2008 these behaviors violated the medical practice act or were the subject of a lawsuit, they were either ignored or addressed through informal advice offered by a colleague in authority.

Some resources now exist to remediate such behavior. Several national organizations teach communication skills, though there are few published reports of interventions designed for physicians with deficient skills ${ }^{1}$. State boards of medical examiners have addressed psychiatric or substance use disorders when they are identified. There are few programs ${ }^{2}$ or resources to address disruptive physician behavior ("an aberrant style of personal interaction... that interferes with... the process of delivering good care. ${ }^{3 \text { ") }}$ before it rises to the attention of these disciplinary agencies. While communication knowledge and skills are clearly teachable, a model for understanding and addressing disruptive behavior is lacking. Personality and contextual factors may influence what emerges as disruptive behavior; thus, effectively remediating disruptive behavior may require addressing the organizational structures in which problem behaviors become manifest in addition to interpersonal skills.

This paper describes the development and implementation of a coaching approach to help organizations and physician/ clients address issues related to impaired communication skills. The model taught to physician/clients is described in Table 1 . The process of teaching this model is described in the Comment section for each stage of the consultation. Most of these physicians generated a pattern of complaints by patients or colleagues; some were referred by their supervisors because of poor productivity attributed to poor communication skills; a few were self-referred. Five fit the definition of "disruptive" physician. The author identified various sub-types of skill deficits, developed a coaching approach, and developed a standardized evaluation form. Evaluations are requested of the referring party and the physician/client approximately 3 months after the consultation is completed. Thirty-three physicians have been referred since 1999. Outcomes are presented for 13 referrals for which standardized evaluations have been completed.

Trained as an internist, the consultant completed a fellowship designed by the American Academy for Communication in Healthcare to train teachers of communication skills. As medical director of a CME organization that provides this training, he has been regularly contacted by administrators who have identified "communication skill deficits" in health professionals.

\section{PARTICIPANTS}

Referrals to the consultant derive from four sources:

1. The consultant is a part-time medical director for a regional non-profit organization that offers $\mathrm{CME}$ programs 
Table 1. Resolving Disagreements: Model and Skills

\begin{tabular}{l}
\hline Models and skills \\
1. Elicit the other person's perspective \\
a. Identify belief model \\
b. Identify emotions \\
c. Identify behavioral expectations \\
2. Acknowledge the other person's perspective \\
a. Active listening \\
b. Empathy skills \\
3. Present your own perspective: beliefs and expectations \\
4. Identify common goals \\
a. First, identify the situation you both are trying to achieve \\
b. Then, negotiate the method(s) for achieving that state \\
5. Set Boundaries \\
a. State boundaries in professional terms (practice guidelines, policies, \\
external constraints), rather than personal terms (blaming) \\
b. State what is inside rather than outside your boundaries
\end{tabular}

in communication skills in the Pacific Northwest. He is sometimes contacted regarding health professionals whose needs may not be addressed by standardized communication programs.

2. The consultant is a part-time communication specialist within the organizational development department of a northwest regional healthcare delivery system. Referrals may come from supervisors of units within the hospital, medical directors of its clinics, or through the medical staff affairs office.

3. Clinics and hospitals in the northwest also request consultation directly.

4. Rarely, physicians self-refer (three have done so to date)

\section{CONSULTATION PROCESS}

Initiating a Consultation. The initial contact is usually made by the medical director or non-clinical administrator of a clinic, the chief of service within a hospital system, or, less frequently, by the physician him- or herself. The nature of the perceived problem is described, and the consultant requests that the referred physician contact him directly to initiate the consultation.

\section{Comment}

An important goal of this initial conversation is to help the referring organization clarify its goals. A clear understanding of the respective responsibilities of the referring organization and the referred physician are critical to a positive outcome. The process outcome of requiring the physician to "take a communication course" has an extremely low probability of succeeding. The physician/client and his or her organization must agree that the behaviors contributing to the referral will change. If the organization is unwilling to attach significant consequences to failure to change (such as termination from the practice, not becoming a partner, or loss of admitting privileges), the likelihood of success is significantly diminished. The organization may be reluctant to attach such conse- quences for fear of losing a skilled or productive clinician or for fear of litigation. Since physicians generally prefer the status quo, a similar reluctance on the part of the organization often creates an alignment against change and alters the relationship of the physician/client to the organization and to the consultant. At a minimum, the consultant attempts to clarify options. While generally accepting the referral, the consultant sometimes finds himself taking a "Stages of Change" ${ }^{5}$ approach with a "precontemplative" organization not yet ready to commit to owning a part of the solution-he expresses concern that the target behavior may not change until the institution's stance changes.

Depending on the context, the referring organization may have various degrees of leverage to compel change. For example, the physician may not be employed or may have unique skills that the organization is reluctant to risk losing.

Regardless of who pays for the consultation, the consultant has two clients, the referred physician and the referring organization. Usually the organization pays for the consultation directly or through CME funds. While health care benefits may be used by mental health practitioners, the consultant uses an educational, not a treatment, model. Less frequently, a physician makes the initial contact and pays for the consultation, in which case she/he becomes the sole client and a frank discussion of goals and commitment to change is critical. In this situation, the consultant emphasizes that if the sole goal is satisfying an external requirement to take a course, recurrent interpersonal difficulty is likely. If the index problem re-emerges, the physician may become more willing to make a genuine commitment to change.

\section{INITIAL EVALUATION}

During the initial conversation with the referred physician, the consultant elicits the clients' goals (and recounts those of the organization), describes the consultation process itself and practical issues such as fees and confidentiality.

\section{Comment}

The relationship with the physician/consultant is the most important contributor to success. While the process is framed as education, in truth it is a therapeutic relationship, not unlike the patient-physician relationship. Empathy, genuineness, and unconditional positive regard are the most transformative elements of such relationships ${ }^{4}$. In fact, at a meta level, this relationship models the relationship the physician/client will strive to emulate with patients and colleagues.

The consultant assumes the roles of coach, mentor, or teacher, but for several reasons the referring source must remain the sole evaluator of success. Contextual factors are critical determinants of professional behavior ${ }^{6}$, and the goal is change within the pressured workplace, not in the consultant's office. In addition, when the consultation is framed as an asset to solve the physician/client's employment dilemma, he or she is less likely to direct resentment toward the consultant, which in turn improves the working relationship.

Confidentiality is critical to the physician/client's honest disclosure of events and his or her personal reactions to those 
events. Emergent self-awareness is often emotional in nature. The consultant discloses only two things to the referring organization: 1) whether the work is occurring and 2) if he thinks progress is being made or whether another type of consultation is necessary.

The differential diagnosis of the physician/client's problematic behavior includes substance use disorders, mental illness, an interpersonal skill deficit, personality disorders, and both work or non-work related stressors. The consultant performs an informal assessment of these domains during the initial interview and may refer the client for a more comprehensive assessment in some circumstances.

\section{THE COACHING PROCESS}

The consultant has developed a simple communication model (Table 1) that emphasizes active listening and negotiation skills. These skills are not unique; they are found in most communication models. Since the model itself is straightforward, the bulk of consultation time consists of analyzing how the barriers to implementation (the physician/client's own emotions, defensiveness, and reluctance to share control) cause troublesome interactions. For the most part, what clients are trying to communicate in problematic encounters can be validated. Their challenge is how to communicate that message respectfully and professionally. During the first visit, the consultant spends $1.5-2$ hours discussing the consultation process and presenting the model. Subsequent visits are 1 hour in duration, spread 2-8 weeks apart. Between sessions, the client attempts to implement the model in challenging circumstances. Successes and challenges are discussed at the subsequent visit until the model is mastered. Typically, the client's greatest challenge is communicating an appreciation of others' perspectives (Step 2) and in setting boundaries in a respectful way (Step 5). Most often as they practice acknowledging others' perspectives, their own view of what constitutes "the truth" becomes less black and white. In other cases, the challenge is more to identify what triggers behavior that gets the learner in trouble.

\section{Comment}

While the model is simple, effective implementation in challenging circumstances is not. It is more difficult to unlearn established patterns of dysfunctional behavior than to learn an effective strategy de novo. Especially in the beginning of the work or when particularly challenging elements of the model are recurrently encountered, the consultant will ask the physician/client to focus on one or two specific elements for the next session.

Since the skills are interpersonal, not medical, clients who have troublesome interactions in their professional lives often have difficulties in their personal relationships as well. Clients often find implementation of these skills rewarding in their personal, as well as their professional lives. Sometimes clients benefit from consulting other professionals concurrently, such as anger management counselors or mental health professionals.

Shadowing the client in his or her work environment could be useful but is also expensive. To date, the consultant has not found this necessary.

\section{TERMINATING THE CONSULTATION}

The consultation generally lasts 3-12 months, 4-10 sessions, although the work is lifelong. When the client and consultant agree that the model has been adequately mastered, evaluations are completed by both the physician/client and the referral source. The consultant contacts the physician in 6 months to see if a "refresher" would be useful.

The following two "cases" are amalgams of real consultations.

\section{Consultation \# 1: An Internist with "Communication Problems"}

A 30-year-old internist was referred by the medical director of her clinic for communication skills training, because patients complained she "didn't listen." A graduate of an American residency training program, she immigrated to the US from Vietnam with her parents at age 6. Her medical director judged her to be a competent and caring physician who had difficulty accepting the requests of some of her patients and who didn't possess culturally acceptable skills to say, "No." Her patients sometimes had difficulty understanding her slight accent.

The medical director informed the physician at her annual review that her expectation of becoming a full partner at the end of the following year would be contingent on her improving her patient satisfaction ratings.

The physician was ashamed that she was having difficulty. While she felt her patients were sometimes unreasonable and judged her communication deficits partly based on her ethnicity and accent (as well as their provincialism), she also felt there was a component for which she was responsible, wanted to stay in her practice, and was dedicated to improving.

By the end of three visits (2 $1 / 2$ months) the consultant and physician agreed that she had mastered the model, but she was still having difficulty with interactions in which she thought the patient was being unreasonable. By this she meant that the patient had not accepted adequate responsibility for controlling those aspects of his or her illness over which the patient had control and instead asked her to compensate by either prescribing an opioid or writing a work excuse. In a particularly poignant moment, after being asked whether there were other situations in which she felt similarly, the physician acknowledged that in her own family, a hard work ethic was the most valuable character trait. This is what had allowed her to educate herself and help her family emigrate to America after the Vietnam War. They agreed that not all people had such capacities or character. By working on step 5 of the model, Setting Boundaries in a professional way, as well as by learning a new model, The Stages of Change, the physician gradually became more comfortable with her most difficult patients-she was able to be clear about her own boundaries while helping patients assume more responsibility for themselves.

After five sessions, the physician and consultant agreed that their work was complete. She had no further patient complaints over the following several months. However, when the consultant contacted her 6 months later, she requested a follow-up visit. There were a few situations which she sensed had been problematic, and while they didn't result in complaints, she felt she probably could have done better. They 
discussed these situations, the consultant offered some suggestions, then they role-played the situation, with the consultant playing the patient.

\section{Comment}

This case highlights a well-meaning practitioner, often a primary care practitioner, who either never learned important interpersonal skills or who skills deteriorate under stress. Sometimes a mismatch of expectations emerges when the culture in which the person grew up or was trained clashes with that in which the physician practices. Examples might be international medical graduates or practitioners who train in an urban area but practice is a rural one. While this can be framed as a cultural sensitivity issue, in truth all the circumstances addressed by this article derive from a deficiency in "perspectivetaking skills", the inability or reluctance to validate other points of view. Generally these situations are remediable unless the practitioner holds strongly to culturally derived judgments.

\section{Consultation \#2: A "Disruptive" Surgeon}

A 40-year-old general surgeon was referred by the medical staff affairs president for a repeated pattern of disrespect to ancillary health professionals. He yelled at nurses in the operating room and in the intensive care unit when they failed to meet his expectations for patient care. In the operating room, there were only certain nurses with whom he would operate, and one recently recruited intensive care nurse he berated had quit.

The surgeon had a long history of disrespectful interactions with nurses, unit secretaries, and more junior colleagues. Complaints led to many conversations with medical staff presidents and chiefs of service, during which he expressed some remorse and promised to try to do better. For several months, the behavior would diminish only to reemerge. After a valued nurse supervisor quit because she concluded that the administration would never effectively deal with his behavior, the chief of the medical staff informed the surgeon that the medical executive committee had decided that admitting privileges would not be renewed if another complaint emerged. When the surgeon complained that he had been this way for years and now the hospital was "changing the rules," the president acknowledged that while he was a valued clinician and contributed strongly to the hospital's bottom line, indeed the rules had changed, and such behavior would no longer be tolerated.

The surgeon was at first hostile, defensive, and unwilling to do more than "show up" for visits. The physician/ consultant validated his sense of unfairness at having to change behavior that had previously been tolerated, albeit reluctantly. He also clarified the boundaries of confidentiality and his primary goal, to help the physician/client succeed in practice. He acknowledged that the decision to proceed was the surgeon's choice, as he himself had no stake in the outcome. He then asked the surgeon to consider the likely outcomes if they simply met a few times, but his behavior didn't change. When the surgeon finally lowered his defenses enough to admit he was concerned that he might eventually lose admitting privileges, the consultant asked how he could be useful. They agreed to explore new options for the surgeon's behavior when he felt frustrated with his coworkers. As this conversation took 90 minutes, they agreed to start in 2 weeks.

Some situations which previously would have led to a conflict, and predictably a complaint, decreased in frequency. Some co-workers, especially the more senior nurses, commented on the change in his behavior. However to the newer OR nurses, who were trained in a less hierarchical era, still seemed "unreasonably assertive," and he continued to struggle with them. They didn't seem to appreciate the changes in his behavior, and at times he found himself yelling with no inkling that the interaction had been about to deteriorate. He felt these nurses were holding "old grudges" and felt hopeless that anything he could do would change the outcome. After some reluctance, the surgeon agreed to directly seek feedback from these nurses. He disclosed separately to many of the nurses in the OR, including the ones he felt were prejudiced against him, that he was working on improving his professional interactions. He asked them to let him know when they thought his tone was rude or disrespectful. He was then able to become alert to risky moments and alter his approach before the interaction deteriorated.

After seven sessions, the surgeon clearly understood the model and could apply it in discussions and role plays with the consultant. He terminated the consultation before the consultant thought he was ready. In practice he sometimes slid into his old, problematic behaviors. In about half the slips, he was aware at the time that he was not responding optimally. The rest of the time, he was unaware he was in trouble. Complaints diminished markedly but did not resolve. He requested from the medical staff president that his probationary status be removed. The medical executive committee decided that that could not happen until complaints were absent for 3 years.

\section{Comment}

Case 2 demonstrates a practitioner who demonstrates a pattern of behavior which has historically been tolerated among technically skilled practitioners. Expectations for change represent a "change in the rules of engagement" and often produce resentment. Because the patterns of problematic behavior are deeply ingrained, they will reemerge if surveillance or consequences are removed. There is a risk that the physician will litigate or resign, and a well considered, clear institutional policy reviewed by legal staff should precede action. Organizations and their officers may not have significant experiences in addressing these situations, which makes it critical to engage the physicians through policies and procedures rather than as unique individuals, so that one doesn't have to re-invent the wheel with each case. This approach also makes the problematic behaviors rather than the individual the focus of concern. 
Table 2. Client Specialties

\begin{tabular}{ll}
\hline \hline Specialty & Number \\
\hline Internal medicine & 11 \\
Obstetrics/Gynecology & 4 \\
Family practice & 2 \\
Orthopedics & 2 \\
General surgery & 1 \\
Neurology & 1 \\
Neurosurgery & 1 \\
Rheumatology & 1 \\
Emergency medicine & 1 \\
Pediatric cardiology & 1 \\
Pediatric intensivist & 1 \\
Plastic surgery & 1 \\
Adult nurse practitioner & 1 \\
Physician assistant & 1 \\
Administration (Pediatric MD) & 1 \\
Nursing (Hospital) & 1 \\
\hline
\end{tabular}

\section{OUTCOMES}

The consultant has completed 31 health professional consultations over 7 years. Generally 2-3 consultations are ongoing at any one time. No standardized data is available for the first 14 consultations, which occurred while the model and a standardized evaluation approach were being developed. Specialty data for the entire sample is shown in Table 2. (Two current clients are not included.) The specialty distribution more likely reflects referral sources than the distribution of communication difficulties across specialties. Most consultations lasted 4-6 hours (range 1.5-10 hours). Only three physicians initiated a consultation without a problem having been identified by others.

For most consultations, an internalized set of skills could be applied and monitored by the physician/client by the completion of the consultation process. For some consultations, physician/clients must always be monitored in order to prevent reemergence of problematic behavior. Regardless, when the physician/client and consultant have agreed that achievable goals have been met, the consultation is terminated. Only two clients terminated the relationship before the consultant felt necessary work had been completed.

Standard evaluations (available upon request) were returned 1-3 months after completion of the consultation. Not all evaluations were returned, but they were sent to all participants and their supervisors, regardless of whether the consultation was prematurely terminated. Data for 13 consultations are presented in Table 3. Physician/clients and supervisors were highly satisfied with the outcomes. On a Likert scale (range, 1-7), with 7 expressing "high satisfaction," physician/clients rated the consultation in the 5-7 range (mean, 6.3), and supervisors rated the consultation in the 6-7 range (mean, 6.7). Many of the physician/clients had no additional complaints in the follow-up period, a few had a couple, and one had more than three. This client was fired. One client changed jobs; and all other participants, to the consultant's knowledge, continued to practice in their same position. One physician changed settings within the same healthcare organization. Follow-up information is not available for one of the participants who prematurely terminated the consultation. Physician/clients most frequently identified the communication model as the most useful part of the consultation; supervisors most frequently indicated that they observed increased flexibility and decreased conflict/complaints involving physician/clients.

\section{CONCLUSION}

A simple coaching model for interpersonal communication can remediate problematic interactions between health professionals and their colleagues or patients. Commitment of the learner, professional consequences for lack of success, and a confidential, supportive coaching relationship are the most important elements for success. With a straightforward coaching approach, health care workers can increase satisfaction in their personal and professional lives, and their organizations can retain productive, workers while minimizing chaos is the workplace.

Strategies that can help organizations transform struggling physicians into successful practitioners are to clearly define behaviors that are unacceptable, develop clear policies about how they will be addressed, and cultivate a cadre of skilled consultants to support these practitioners.

A limitation of this approach is the heterogeneous nature of the communication deficiencies. Future interventions to assist struggling physicians should focus on tailoring new types of resources to the specific needs of the physician. These might include mentoring by a colleague in the workplace, group sessions with struggling physicians, and psychological resources.

Another limitation of this report is that outcomes rely on a surrogate marker of physician behavior, observations by the physician's supervisor or others who report them to the supervisor. Future studies would benefit from direct observation of the physician's behavior via videotape or from the patient's point of view.

Similarly, a limitation of this approach is that the consultant is divorced from the work setting, the context of interest for problematic physician behaviors. Rigid confidentiality has precluded direct communication with supervisors. More recently, the consultant has experimented with meetings that include both the physician and his or her supervisor in setting goals, outcome expectations, and clarifying issues of confidentiality. This works well when a behavior change is mandated as a condition of employment, less well when consultation is suggested by a colleague who also happens to have administrative respon-

Table 3. Satisfaction with Consultation

\begin{tabular}{lll}
\hline \hline & Learner & Supervisor \\
\hline Median satisfaction with consultation (1-7) & $\begin{array}{l}6.3 \\
13\end{array}$ & $\begin{array}{l}6.7 \\
8\end{array}$ \\
Completed evaluations & \begin{tabular}{l} 
S.3 \\
\hline
\end{tabular}
\end{tabular}


sibilities (such as a physician director of a hospital unit). A model in which organizational resources in the work setting extend and reinforce the consultation process would be ideal. Organizational development departments are ideally suited to this role. While organizational development specialists are well suited to communication coaching, they are not typically physicians and may experience an additional layer of defensiveness from a physician/client.

Finally, this report reflects the experience of a single consultant located in the Pacific Northwest. Without additional testing by multiple consultants in various regions of the country the results should be interpreted as preliminary.

Acknowledgement: I appreciate the support and manuscript suggestions of Dr. Wendy Levinson.

Conflict of Interest: None disclosed.
Corresponding Author: Barry Egener, MD; The Foundation for Medical Excellence, 1639 SW Skyline Blvd., Portland, OR 97221, USA (e-mail: begener@lhs.org).

\section{REFERENCES}

1. Stein T. A decade of experience with a multiday residential communication skills intervention: has the outcome been worth the investment? Permanente J. 2007;11:30-40.

2. Samenow CP, Swiggart W, Spickard A. A CME course aimed at addressing disruptive physician behavior. Physician Exec. 2008;Jan.Feb.: 32-40.

3. Lang DA, Jara JB, Kessenick LW. The Disabled Physician: ProblemSolving Strategies for the Medical Staff. Chicago: American Hospital Publishing, Inc.; 1989

4. Rogers CR. The necessary and sufficient conditions of therapeutic personality change. J Consulting Psychology. 1957;21:95-103.

5. Prochaska, JO, DiClemente CC, Norcross JC. In search of how people change: applications to addictive behaviors. Amer Psychologist. 1992; September, 1102-1114.

6. Ginsburg S, Regehr G, Hatala R, et al. Context, conflict, and resolution: a new conceptual framework for evaluating professionalism. Acad Med. 2000;75:S6-S11. 